\title{
Study of Recent Literature on Weather Monitoring Systems
}

\author{
Madhuri P. Patil \\ Dept. of ETC, \\ Godavari COE, \\ Jalgaon, MS, India
}

\author{
S. R. Pachpande \\ Dept. of ETC, \\ J T Mahajan COE \\ Faizpur, MS, India
}

\author{
J. P. Chaudhari, PhD \\ CHARUSAT Space \\ Research and \\ Technology Center, \\ Changa, Gujarat, India
}

\author{
K. P. Rane, $\mathrm{PhD}$ \\ ETC Department \\ Godavari COE \\ Jalgaon, MS, India
}

\begin{abstract}
Climate observing has critical influence on mankind. Gathering of the various data of fleeting elements of the climate variations is extremely noteworthy. The essential point of this paper is to build up an installed framework to outline a climate observing framework which empowers the checking of climate parameters. This type of frame work includes various sensors involving temperature, Humidity, wind speed, wind bearing information can be signed into cloud so that any one (validated individual) from wherever can watch the particular information. If there should be an occurrence of any catastrophes like flame, substantial downpour, overwhelming wind, temperature or moistness might be wild, in these cases the moment data can be passed on all through the world utilizing cloud to the verified people, regardless of the fact that his equipment is wrecked in crisis.
\end{abstract}

\section{Keywords}

Humidity Sensor, Temperature Sensor, Wind Speed Sensor, Wind course Sensor, Raspberry Pie Board.

\section{INTRODUCTION}

Cloud information can be secured and simple/quick to access. Any nonstop fluctuating information can be signed into cloud to the Automation of Weather Station System can be utilized measure, check and screen the climate parameters to keep the gigantic harm or perils from normal fiascos, in farming zone. A climate station furnishes the office concerning hardware to check, screen and watch the climate conditions. The watched and observed climate parameters data is valuable to make climate figure reports and to examine the climate and atmosphere. In this framework the climate parameters estimations taken are temperature, moistness, wind course, and wind speed. Wind estimations are measure as free of different obstacles as could be allowed, while temperature estimations are taken free from direct sunlight based radiation or protection and stickiness

Estimations are specifically taken from the dirt. The climate parameters estimations are taken through climate sensors for various parameters put in the horticulture zone.

\section{LITERATURE SURVEY}

Cloud Based weather monitoring systems are classified based on technology used as 1) WSN, 2) Satellite, 3) Microcontroller, and 4) Arduino, 5) GSM, 6) Radar, 7) Zigbee, 8) Prediction based system, (9) Sensor Based System, and (10) Camera Based System.

\subsection{Wireless Sensor Network Based System Wireless Sensor Networks (WSNs) [1] includes various sensors distributed spatially with the capacity of communication, processing and computing. The data is sensed and transmitted to the base-station regularly. Here, in real time manner, data is processed and managed. One proposed framework [2] conquers the above restriction by organization of WSN base for different climate advance utilizing virtual sensor and overlay idea. Checking climate information and giving SaaS and interpersonal organization cataclysm cautions in light of choice ID3 system and give cloud validation utilizing secure shell. Similar work [3] gives a conditional summary on WSN with Internet of bothers based on PARASENSE plan. A good arrangement is made for sending continuous applications and for conveying it.}

\subsection{Satellite Based System}

Satellite information is progressively being utilized as a part of conjunction with routine meteorological perceptions in the concise investigation and traditional climate gauge to concentrate data [4].CanSat [5] is a scale reproduction of the outline, creation and dispatch of a genuine satellite. It is described by minimal effort of usage. Climate observing is the utilization of science and innovation to foresee the condition of the climate for a given area. The CanSat assembled can be dispatched and used to monitor neighborhood climate for a range, in a sparing way. Authors have explained on our work on this paper. In this study, the climate satellite is a kind of satellite that is basically used to screen the climate and atmosphere of the Earth. Weather satellite pictures are always helpful in checking the volcanic powder cloud [6].

\subsection{Microcontroller Based System}

The basic point of a work based on microcontroller [7] is to manufacture an implanted framework to plan an air checking framework which empowers the saw of climate parameters in an industry. This type of work includes different sensors like Gas sensors, temperature sensors, and dampness sensors which were observed with the use of ARM 9 LPC1768 microcontrollers. The following framework utilizes a complex circuit developed with ARM 9 processor. Embedded C programming is used. Scheduling is done with the use of JTAG in association with ARM 9 processor. 


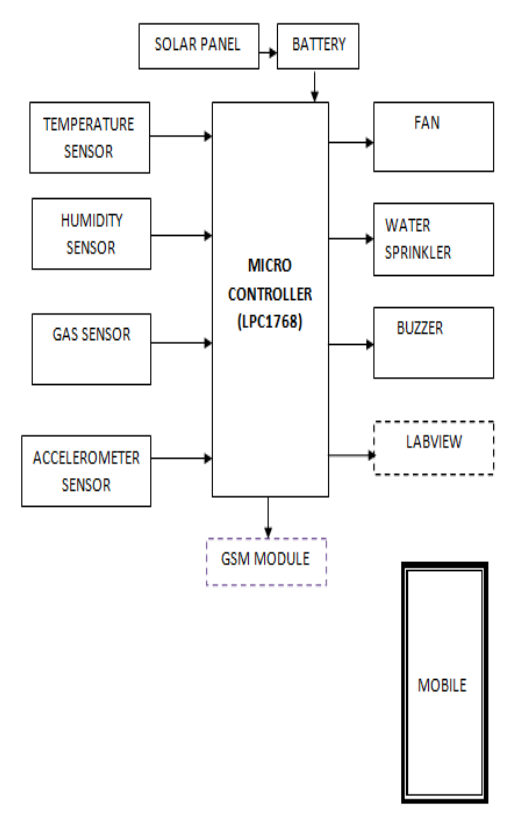

Fig.1: Block diagram of Microcontroller System

In a work presented during [8], it screens and shows the temperature, weight and similarly dampness of the sky, utilizing simple and advanced segments. The following Fig. 2 shows the microcontroller connected to sensor which provides digital signal to the microcontroller. Sensor module itself converts the analog signal into digital signals and sends serially to the microcontroller.

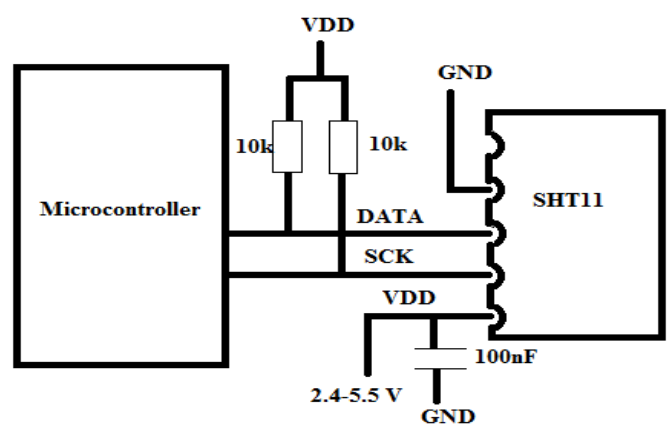

Fig.

2: SHT11 Connections with Microcontroller

The key point of a similar work [9] is to build up an implanted framework to plan a climate checking framework which empowers the observing of climate parameters. This type of framework includes various sensing devices like Humidity, temperature, wind speed, wind heading information can be signed into cloud so that any one (validated individual) from wherever can watch the particular information.

\subsection{Arduino Based System}

Through a specific framework [10,11], it can naturally gather the data about stickiness and temperature. Through this framework authors can naturally gather the data about stickiness and temperature. The points of interest are put away in a database and as per present and past information authors can deliver the outcomes in graphical way in the framework. The circuit diagram is shown in Fig. 3 describes the interdependent functionality of the components and their output.

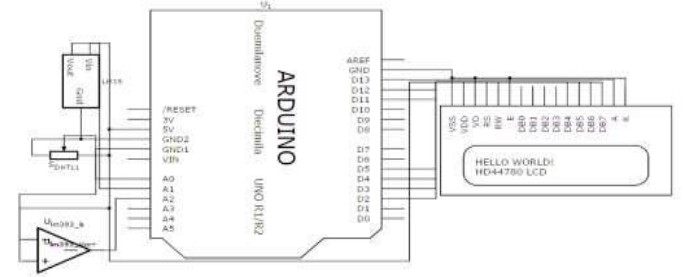

Fig.3: Arduino based System

\subsection{GSM Based System}

In GSM based systems[12,13], a gadget for ongoing climate observing is displayed to screen the constant temperature, environmental weight, relative dampness and air's dew point temperature through such system which is utilizing simple and advanced parts. In the following system of Fig 4., digital signals are obtained from analog signals and database is altered according to the program designed for displaying userfriendly outcomes in terms of pressure on a display.

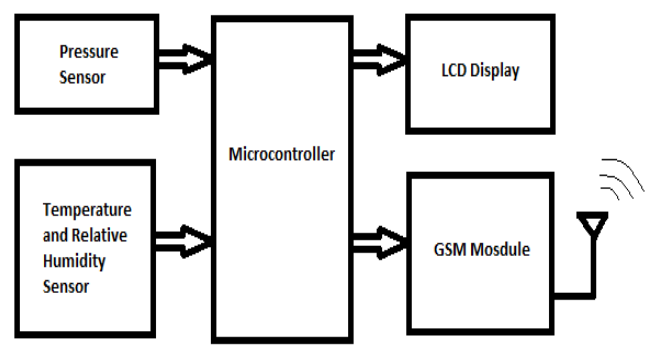

Fig. 4:Weather Monitoring System with Transmitter

\subsection{Radar Based System}

In Radar based systems like [14, 15], the creators introduced a technique that coordinates both of the information sources to give strategic and arranged climate radar.

\subsection{ZIGBEE Based System}

To create sensor networking and weather station monitoring system without human mediation, utilizing Wireless ZigBee Technology [16, 17]. Zigbee is the most recent remote climate checking method. The previous checking frameworks of Weather Monitoring System are manual that time.

\subsection{Prediction Based systems}

In a prediction based system [18], authors proposed a methodology for monitoring transient climate conditions based on semantic and geospatial coherent cross-disciplinary. In this, demonstration of individuals driven detecting system is given to improve the accuracy of the system and the legitimacy of information collected using regular sensor is affirmed. Similarly, Mattlach et. al. [19] assessed the conventional climate armada as an asset for atmosphere monitoring. The wave soul range, which all NDBC climates floats routinely report hourly. It contains a lot of data with respect to the starting point, quality and term of sea tempests. Such estimations are delivered from basic accelerometers originating from an adult, settled innovation. SWAP is another one method [20] which will execute as an operational sun based observing instrument for space climate forecasting. The LYRA information will make profitable sun powered checking data, for agent space climate now throwing and testing. Similarly in another prediction based system, the control outfit figure with starting condition instability, is handy yet under dispersive. To enhance the unwavering quality of the outfit gauges, the control group is supplemented with 1) annoyed side perspective limit conditions; or, 
representation blunder representation utilizing either 2) stochastic active soul backscatter or 3) stochastically bothered parameterization propensities [21]. Multi-physics and a stochastic active fundamental backscatter arrangement are utilized in a similar system to speak to model instability in a meso-scale troupe conjecture framework utilizing the Weather Investigation and Forecasting model [22].

Table 1. Weather Monitoring Systems using Communication Media

\begin{tabular}{|c|c|c|c|}
\hline Sr no & Techniques & Ref & Problems \\
\hline 1 & WSN & $\begin{array}{l}{[1],} \\
{[2],} \\
{[3]}\end{array}$ & $\begin{array}{l}\text { Specific substitution of } \\
\text { sensor, lower speed, } \\
\text { less secure because } \\
\text { programmer can read } \\
\text { information like } \\
\text { username and } \\
\text { password, }\end{array}$ \\
\hline 2 & Satellite & $\begin{array}{l}{[4],} \\
{[5],} \\
{[6]}\end{array}$ & $\begin{array}{l}\text { Tremendous initial cost } \\
\text { noise and interference, } \\
\text { propagation delay, time } \\
\text { delay lessens } \\
\text { efficiency. }\end{array}$ \\
\hline 3 & GSM & $\begin{array}{c}{[12],} \\
{[13]}\end{array}$ & $\begin{array}{l}\text { Various client offers } \\
\text { same bandwidth } \\
\text { transmission experience } \\
\text { interference, is because } \\
\text { of heat beat } \\
\text { transmission, GSM has } \\
\text { settled max call locales } \\
\text { range up to } 35 \mathrm{~km} \text { that } \\
\text { is exceptionally limited. }\end{array}$ \\
\hline 4 & Radar & $\begin{array}{l}{[14],} \\
{[15]}\end{array}$ & $\begin{array}{l}\text { Time radar can take up } \\
\text { to } 2 \text { sec to bolt on, radar } \\
\text { has wide pillar spread, } \\
\text { more obstructions } \\
\text { sources. }\end{array}$ \\
\hline 5 & Zigbee & $\begin{array}{c}{[16],} \\
{[17]}\end{array}$ & $\begin{array}{l}\text { Shorter range, lesser } \\
\text { complexity, less } \\
\text { information speed, high } \\
\text { cost. }\end{array}$ \\
\hline
\end{tabular}

The computation of environment forecast rightness has dependably been a troublesome subject to address for some reasons. In a novel study [23], a simple semi target strategy is utilized to look at the exactness of zone prediction. Zone forecasts were picked in light of the fact that these expectations are ordinarily what the general population will get either straightforwardly or in a roundabout way from various media outlets. The Meteorological Development Laboratory (MDL) is a novel approach which has been developed and implemented a frame work based on flight environment gauge in recent work [24].It is executed by each hour and collected the data for about $25 \mathrm{~h}$ for validating the requirements of the National Weather Service (NWS).Based on the temperature field and wind fields, the land dispersion of the expectation sways (FIs) at $500 \mathrm{hPa}$ and10-m stature is arranged in a novel prediction system [25]. This work demonstrates the enhancement of the NCEP GFS wind and temperature by acclimatizing the surface wind recoveries with the use of Wind Sat satellite.

\subsection{Sensor Based System}

In a recent work [26], Mittal et. al. planed to distinguish the topographical ranges for sun based and wind vitality eras with ease. There framework depends on remotely worked framework with sensors, which accumulates climate data and transmits measured qualities to the ground. The framework is worked by battery, and is required to keep running with an expanded life period. Static sensor hubs and submerged sensor web are connected in ecological verification in a novel study. By consolidating adding a sensor system and a technique of distributed computing [27], the submerged sensor bid can be improved. The climate station is designed recently [28] which has a gathering of sensors for measuring wind pace and bearing, air temperature, relative dampness and precipitation. A snowfall connector can be continuing the precipitation gage that permits estimation of the water fulfilled of snow amid winter months. DCOMP is a novel system [29] having a set up to keep running on sensors with comparative channel settings and has been effectively practiced on most current meteorological imagers. This standard makes DCOMP especially profitable for air research. Correlations with the Moderate Resolution Imaging Spectroradiometer (MODIS) gathering 5 dataset are utilized to figuring the execution of DCOMP.

During 2016, in a recent work [30], wind sensor, wind direction sensor, humidity and temperature sensor are used for sending the real time data on Thing Speak cloud Which can be easily observed and analyzed to authorized person or may be publically open. It uses Raspberry Pi development board used earlier by many authors for user-friendly works [31, 32]. Arm $7[33,34]$ is an efficient processor which is generally used for real time operation in many applications.

\subsection{Camera Based System}

With a unique sort of camera and computerized multi-image photogrammetric framework, it's currently conceivable to takeout Digital Elevation Models (DEM) with capturing an image by the camera [35].Using such strategy; the plane is may not be limited to flight way straightly. And it may go straightforwardly along objective region. That postulation presented the work hypothesis of computerized photographic visibility framework (for short is DPVS), edge of framework, structure of equipment and programming stream, at last correspondence amongst host and open air cell [36].

\section{SUMMARY}

Various recently available weather monitoring systems were studies and found that they are categorized based on various techniques summarized in Table 1 and Table 2. Some systems are based on the communication media used and others are based on the processor and techniques. There are various communication's channels used in different field of embedded systems recently based on GSM based [34], GPRS [34], WSN network, etc.

Table 2. Weather Monitoring Systems using Processor and Technique Used

\begin{tabular}{|l|l|l|l|}
\hline $\begin{array}{l}\text { Sr } \\
\text { no }\end{array}$ & Techniques & Ref & Problems \\
\hline & & & \\
1 & Predictions & {$[18]$,} & $\begin{array}{l}\text { Climate prediction } \\
\text { correctness has been } \\
\text { difficult to address. Fault } \\
\text { prediction occurs due to } \\
\text { climate changes. }\end{array}$ \\
& & {$[21],[22],[24],[24]$} \\
& & {$[23]$} & \\
\hline
\end{tabular}




\begin{tabular}{|l|l|l|l|}
\hline 2 & Sensor & $\begin{array}{l}\text { [26],[27], } \\
{[28],[29]}\end{array}$ & $\begin{array}{l}\text { A sensor network may } \\
\text { require a lot of additional } \\
\text { wiring to be installed if } \\
\text { sensor are wired \& if sensor } \\
\text { are wireless much more } \\
\text { expensive } \\
\text { - }\end{array}$ \\
\hline 3 & Camera & {$[30],[31]$} & $\begin{array}{l}\text { For vertical photography } \\
\text { which require clear sky, no } \\
\text { cloud \& is humped by } \\
\text { strong thermal activity in } \\
\text { the air. }\end{array}$ \\
\hline 4 & $\begin{array}{l}\text { Micro- } \\
\text { controller }\end{array}$ & $\begin{array}{l}{[7],[8],} \\
{[9]}\end{array}$ & $\begin{array}{l}\text { Arm 7 is little, low } \\
\text { power,32 bit uc,3 stage } \\
\text { pipeline, each stage take one } \\
\text { clock cycle as looked at } \\
\text { ARM 9 and ARM 11,ARM } \\
11 \text { is 8 phase pipeline,32 bit } \\
\text { RSC processor with ARM, } \\
\text { Thumb,ISA, SIM and java. }\end{array}$ \\
\hline 5 & Arduino & {$[10],[11]$} & $\begin{array}{l}\text { Structure is drawback size } \\
\text { should be as small as } \\
\text { possible. }\end{array}$ \\
\hline
\end{tabular}

\section{CONCLUSION}

The distinctive frameworks are studied in which how to utilize the various sensors for weather monitoring are analyzed. Many new stockpiling techniques can be utilized by scientists and academician for further examination and forecast all around. Similar to discussed frameworks, many systems can be pictured so can satisfy the today's need. This paper tries to concentrate all late climate checking frameworks extensively.

\section{REFERENCES}

[1] Ashenafi Lambebo, Sasan Haghani, 2014, A Wireless Sensor Network for Environmental Monitoring of Greenhouse Gases, ASEE 2014 Zone I Conference,University of Bridgeport, Bridgpeort, CT, USA.

[2] D. S. Arjun, A. Bala, V. Dwarakanath, K. S. Sampada, B. B. Prahlada Rao and H. Pasupuleti , 2015, Integrating cloud-WSN to analyze weather data and notify SaaS user alerts during weather disasters, IEEE International Advance Computing Conference (IACC), pp. 899-904.

[3] Srinivasa K.G. M.S.Ramaiah. Siddiqui.N. Kumar. A, ParaSense - A Sensor Integrated Cloud Based Internet of Things Prototype for Real Time Monitoring Applications, in region10 IEEE Symposium (TENSYMP), 2015,

[4] S.P.KALSI, 2008, Satellite Based Weather ForecastingIndia, in Wireless Communications and Networking Conference, WCNC-2008.

[5] Gopal G, Harith B, Ritwik Raj Savyasachi ChetanUmadi, May 2016, Weather Monitoring Using Parachute Satellite Can Sat, International Journal of Engineering Science and Computing, Volume 6 Issue .

[6] Kyung Hee Univ; Yongin, South Korea,La The ,Vinh,Dang Viet Hung,Phan Tran Ho Truc, Contextaware Human Activity Recognition and decision making, IEEE International Conference on Networking Applications and services, 2012.
[7] P. Susmithan, G.Sowmyabala, Design and Implementation of Weather Monitoring and Controlling System, International Journal of Computer Applications (0975 - 8887) Volume 97- No.3, July 2014.

[8] Guo X, Song Y, 2010 "Design of Automatic Weather Station Based on GSM Module", International Conference on Computer, Mechatronics, Control and Electronic Engineering (CMCE).

[9] Miss M P Patil, Dr k P Rane, "Cloud Based Weather Monitoring System," International Journal on recent trades in computing in trades in computing \& com., vol 4(5), pp,446-450, 2016.

[10] Karthik Krishnamurthi, SurajThapa, March-April 2015, Arduino Based Weather Monitoring System, Journal of Computer Science, Volume 3, Issue 2.

[11] Amber Katyal1; Ravi Yadav2; Manoj Pandey, "Wireless Arduino Based Weather Station", Journal of Computer Science, Vol. 5, Issue 4, April 2016.

[12] K C Gouda, Preetham V R, M N Shanmukha Swamy, July2014, Microcontroller Based Real Time Weather Monitoring Device With GSM, International Journal of Science, Engineering and Technology Research (IJSETR), Volume 3, Issue 7.

[13] Keshav kumar Singh, 2013, Design of Wireless Weather Monitoring System using GSM, Thesis submitted to Department of Electronics \& Communication Engineering National Institute of Technology Rourkela.

[14] Kelly. W, K. Kronfeld ; T. Rand, 2000, Cockpit integration of uplinked weather radar imagery, published in Digital avionics system conference.

[15] Lo Conti, Francesco, Pumo, Dario, Incontrera, Antonia, Francipane, Antonio, Noto, Leonardo Valerio, La Loggia, Goffredo, 2014, A Weather Monitoring System For The Study Of Precipitation Fields, Weather, And Climate In An Urban Area, CUNY Academic Works.

[16] Nisha Gahlot, Varsha Gundkal, Sonali Kothimbire, Archana Thite, 2015, Zigbee based weather monitoring system, International Journal Of Engineering And Science (IJES), Volume 4 Issue 4 .ISSN (p): $2319-$ 1805 .

[17] Rajdeep Kumar, Sazid Khan, Manik Chand Yadav; S K Dubey, Weather monitoring system", International Journal of Advanced Technology in Engineering and Science Volume 02, Issue No. 05, May 2014,

[18] Phillips W.D, RaytheonLargo, SankarR, Improved transient weather reporting using people centric sensing, Consumer Communications and Networking Conference (CCNC), 2013

[19] Mettlach.T. Na, Stennis, Chung-Chu Teng, Weir, R., LaRue. K, Quality of archived NDBC data as climate records, Oceans, 2008

[20] Defise J.M, Angleur Belgium, Lecat J.H., Stockman Y, Rochu P., 2005, SWAP and LYR,. space weather from a small spacecraft, Published in Recent Advances in Space Technologies.

[21] Chung- Chieh Wang, 2015, The More Rain, the Better the Model Performs-The Dependency of Quantitative Precipitation Forecast Skill on Rainfall Amount for 
Typhoons, Journal of Earth Sciences, National, Volume 143 Issue 5.

[22] Bagiorgas.H.S, Margarita.N.A, Patentalaki.A, Konofaos. N, Dmetrios Matthopoulos, Mihalakakou G, 2007, The Design Installation and Operation of A Fully Computerised, Automatic Weather Station for High Quality Meteorological Measurements, published in Fresenius Environmental Bulletin, Volume 16,Issue 8, pp.948- 962 .

[23] Guo X. \& Song Y, "Weather prediction model" International journal of computer application, Volume 142 Issue.

[24] Judy E. Ghirardelli,2009, The Meteorological Development Laboratory's Aviation Weather Prediction System, NOAA/NWS/ Meteorological Development Laboratory/Office of Science and Technology.

[25] Li Bi,James A. Jung,Michael C. Morgan; John F. Le Marshall, 2010, A Two-Season Impact Study of the WindSat Surface Wind Retrievals in the NCEP Global Data Assimilation System", Assessment of Assimilating ASCAT Surface Wind Retrievals in the NCEP Global Data Assimilation System, Volume Issue139:11, 34053421.

[26] Mittal,D., Vaidya,.B. , J Mathew, 2014, A GSM based low cost weather monitoring system for solar and wind energy generation, International Journal Digital Information and Web Technologies.

[27] Srimathi; C. Soo-Hyun Park, Rajesh. N, "Framework for underwater sensor cloud for environmental monitoring," International Journal of Ubiquitous and Future Networks ICUFN, 2013.

[28] J. Berner; S.-Y. Ha; J. P. Hacker; A. Fournier; C. Snyder, 2011,Model Uncertainty in a Meso-scale Ensemble Prediction System: Stochastic versus Multiphysics, National Center for Atmospheric Research, Boulder, Colorado Volume 139.
[29] W. Dayton St; Madison, 2015, Implementation of the Daytime Cloud Optical and Microphysical Properties Algorithm (DCOMP) in PATMOS-x, Published in Cooperative Institute for Meteorological Satellite.

[30] Miss. Madhuri Prakash Patil, Mr. K P Rane, , 2016, Cloud Based Weather Monitoring System, International Journal on Recent and Innovation Trends in Computing and Communication, Vol. 4, No.5, pp 446-450.

[31] Miss. Pradnya R. Nehete, Dr. K P Rane, 2016, OTP Based Door Lock Security System, International Journal Of Emerging Trends In Engineering And Management Research, vol. 2, no. 2.

[32] Mr. G. A. Thakur, Mr. A. D. Vishwakarma, Dr. K. P. Rane, 2016, Automatic banana hands bunches measuring \& recording Systems," International Journal on Recent and Innovation Trends in Computing and Communication, vol. 4, no. 5, pp. 429-433.

[33] Kausal, M. A., Jadhav, I., Pachpande, S., Rane K. P, 2014, A Paper on RFID in LibraryAutomation, International Journal of Advanced Electronics and Communication Systems.

[34] Shital M. Dharrao, Vijay D. Choudhary, and Kantilal P. Rane, 2016, Intelligent Bus Stand Monitoring and Control, Proceedings of the ACM Symposium on Women in Research

[35] Gleitsmann. L., Kappas. M, 2004, Digital multi-image photogrammetry combined with oblique aerial photography enables glacier monitoring survey flights below clouds in Alaska, International Journal of Geoscience and Remote Sensing Symposium.

[36] JingliWang,Wenfang Zhao; Guohong Liu ; Xulin Liu, 2011, System design of DPVS, International Journal of Electronics, Communications and Control (ICECC). 